\title{
Epstein-Barr virus-positive ileal extraosseous plasmacytoma containing plasmablastic lymphoma components with CD20-positive lymph node involvement
}

\author{
This article was published in the following Dove Press journal: \\ International Journal of General Medicine \\ 22 August 2012 \\ Number of times this article has been viewed
}

\author{
Makoto Saito' \\ Masanobu Morioka' \\ Ko Izumiyama' \\ Akio Mori' \\ Tatsuro Irie' \\ Masanori Tanaka' \\ Yoshihiro Matsuno ${ }^{2}$ \\ 'Department of Internal Medicine and \\ Hematology, Aiiku Hospital, Sapporo, \\ Japan; ${ }^{2}$ Department of Surgical \\ Pathology, Hokkaido University \\ Hospital, Sapporo, Japan
}

\begin{abstract}
We report a case of Epstein-Barr virus (EBV)-positive ileal extraosseous plasmacytoma containing plasmablastic lymphoma components with CD20-positive lymph node involvement. A 34-year-old healthy Japanese male developed intussusception due to an ileal plasmacytoma. The lesion was positive for EBV-encoded small nuclear RNA in in situ hybridization, with the surrounding lymph nodes showing the expression of CD20. Tumor cells in the ileal and lymph node lesions contained high-grade malignant features compatible with plasmablastic lymphoma. Because his abdominal lymph nodes recurred 6 months after resection, he received six cycles of R-CHOP chemotherapy (rituximab, cyclophosphamide, doxorubicin, vincristine, and prednisolone), and had a complete remission. Although his case was complicated by acute promyelocytic leukemia, he has so far survived, recurrence-free, for more than 7.5 years after chemotherapy for extraosseous plasmacytoma.
\end{abstract}

Keywords: ileal extraosseous plasmacytoma, plasmablastic lymphoma, Epstein-Barr virus (EBV), lymph node involvement, CD20, R-CHOP

\section{Introduction}

Extraosseous (extramedullary) plasmacytomas arising in tissues other than bone and bone marrow ${ }^{1}$ are rare; they account for only $3 \%-5 \%$ of all plasma cell neoplasms, and belong to mature B-cell neoplasms in the World Health Organization (WHO)

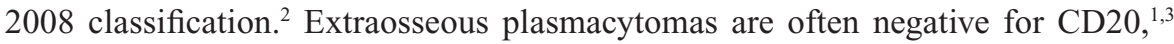
and approximately $80 \%$ of them occur in the upper respiratory tract, such as in the nasal cavities and paranasal sinuses. ${ }^{1,2,4,5}$ Regional lymph nodes were involved in only $2.6 \%$ (4/155 patients) of primary extraosseous plasmacytomas reported in nonupper respiratory tract areas. ${ }^{1}$

Plasmablastic lymphoma (PBL) was included as an independent entity in the 2008 WHO classification. ${ }^{6}$ It is a high-grade malignant mature B-cell neoplasm characterized by frequent development in immunodeficient patients, such as human immunodeficiency virus (HIV)-infected individuals, and by the integration of EpsteinBarr virus (EBV) RNA into tumor cells in $60 \%-75 \%$ of the cases. ${ }^{7,8}$

We report a case of EBV-positive ileal extraosseous plasmacytoma (CD20negative [CD20-]) with regional lymph node lesions (CD20-positive [CD20+]), showing histopathological features partly compatible with PBL; 6 months after resection, abdominal lymph nodes recurred, for which R-CHOP chemotherapy 
(rituximab, cyclophosphamide, doxorubicin, vincristine, and prednisolone) was highly effective.

\section{Case report}

A 34-year-old healthy Japanese male developed intussusception due to an ileocecal tumor, and underwent right hemicolectomy with lymph node dissection in the Department of Surgery at Hokkaido University Hospital.

Grossly, the lesion in the terminal ileum was a $6.5 \mathrm{~cm} \times 4.0 \mathrm{~cm}$ subpedunculated, elevating tumor (Figure 1). Histopathologically, the tumor showed solid growth of prominent nonepithelial cells with eccentrically located nuclei and clear perinuclear cytoplasm (CD138+), consistent with extraosseous plasmacytoma (Figure 2A). In some areas, features compatible with those of PBL, such as plasmablast-like cells and mitotic figures, were observed (Figure 2B). In the dissected regional lymph nodes, there was a proliferation of tumor cells similar to those in the ileal lesion, which included PBL components, suggesting lymph node involvement (Figure 2C). Tumor cells were positive for EBV-encoded small nuclear RNA in in situ hybridization (Figure 2D). The MIB-1
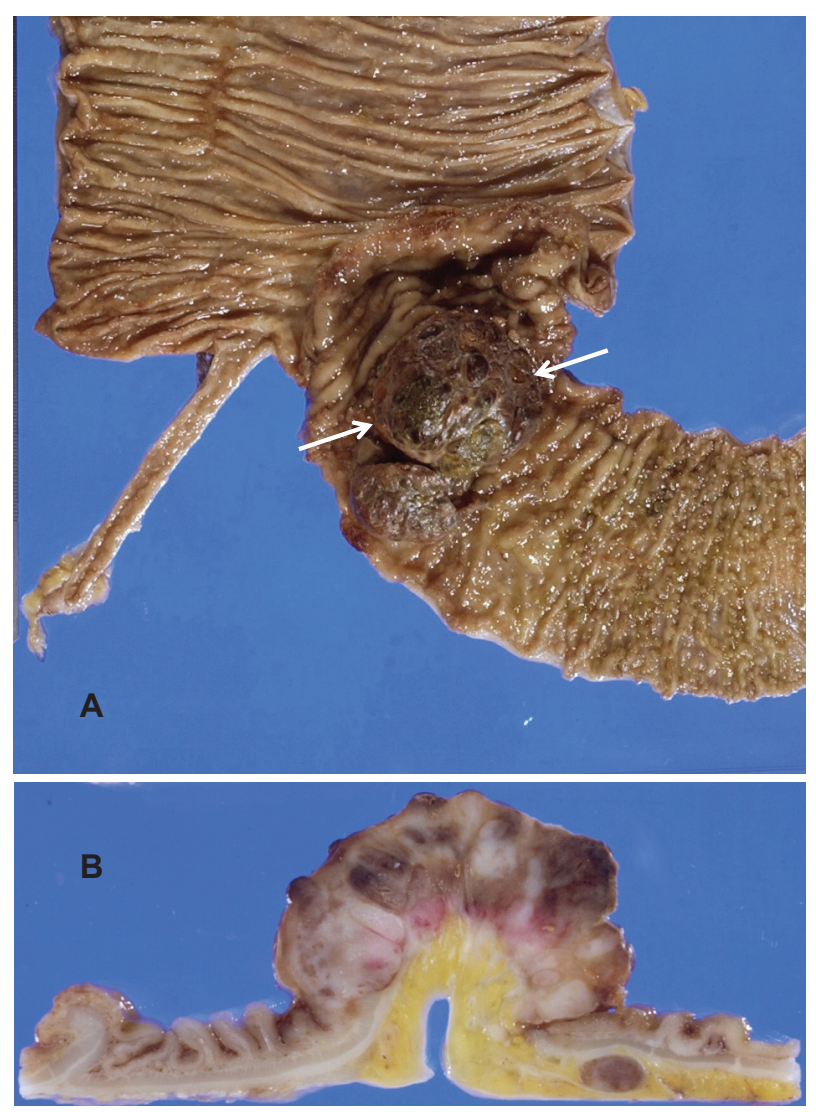

Figure I Gross findings of the primary lesion. A $6.5 \mathrm{~cm} \times 4.0 \mathrm{~cm}$ tumor (A) was observed in the terminal ileum (arrows). The tumor was elevating and had a subpedunculated feature (B).
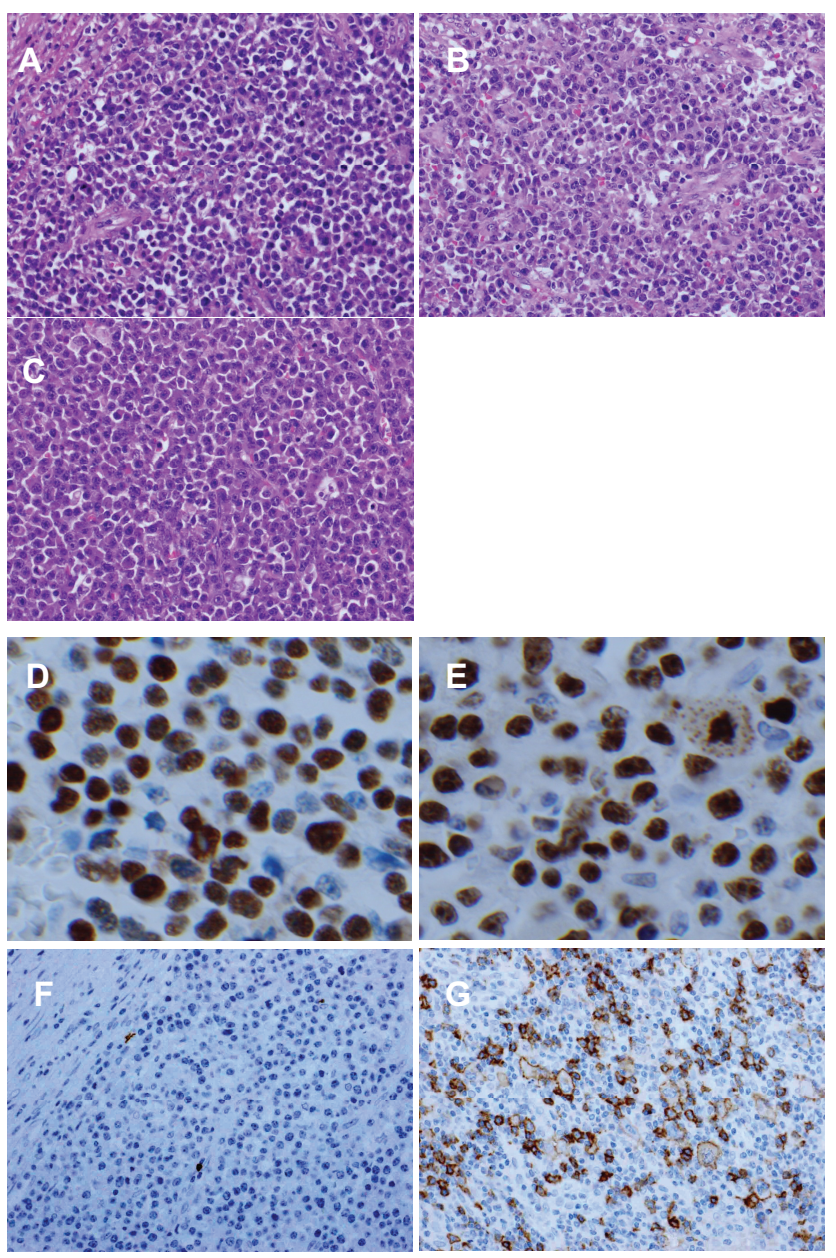

Figure 2 Histopathological findings. In the primary lesion (A), the tumor showed consistent with plasmacytoma. In some areas of the primary lesion (B), plasmablastic lymphoma-like features were observed. In the regional lymph nodes (C), involvement by plasmacytoma cells was observed (D). EBER in situ hybridization showed the tumor cells were positive. MIB-I (Ki-67) labeling index of the tumor cells (E) was approximately $80 \%-90 \%$. Primary lesion (F) was negative. Lymph node lesion (G) was positive.

Notes: Original magnification of $(\mathbf{A}-\mathbf{G}): \times 400$. (A-C) resulted from HE staining, ( $\mathbf{F}$ and $\mathbf{G})$ from CD20 immunostaining.

Abbreviations: EBER, Epstein-Barr virus-encoded small nuclear RNA; HE, hematoxylin and eosin.

(Ki-67) labeling index of the plasmablast-like tumor cells was approximately $80 \%-90 \%$ (Figure $2 \mathrm{E}$ ). Tumor cells of the ileum were negative for CD20 (Figure 2F), whereas atypical, large and clear cells of the lymph node lesions were positive for CD20 (Figure 2G). He was histopathologically diagnosed as having ileal extraosseous plasmacytoma (EBV-positive) with CD20+ lymph node involvement.

After surgical resection, the patient was followed up without treatment. Computed-tomography scans performed at 6 months showed the swelling of several abdominal lymph nodes, such as the para-aortic and mesenteric lymph nodes, which were not seen at surgery, suggesting abdominal lymph node recurrence (Figure 3A). He was admitted to 

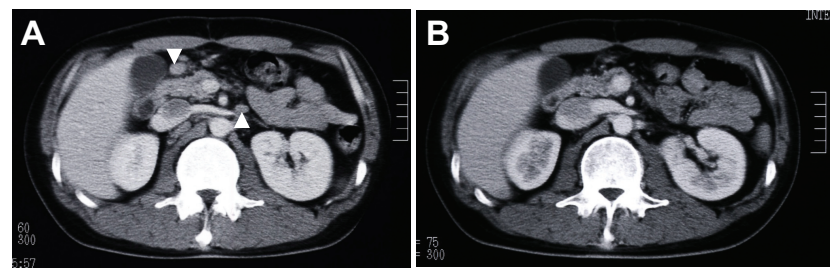

Figure 3 Abdominal computed-tomography findings. (A) The abdominal lymph nodes (indicated by arrow) were observed. (B) The lymph nodes disappeared after $\mathrm{R}-\mathrm{CHOP}$ chemotherapy.

Abbreviation: R-CHOP, rituximab, cyclophosphamide, doxorubicin, vincristine, and prednisolone.

our department to undergo additional therapy. Laboratory examination upon admission showed slightly increased levels of serum $\beta_{2}$-microglobulin $(1.9 \mathrm{mg} / \mathrm{L}$; normal range $0.8-1.7 \mathrm{mg} / \mathrm{L})$ and soluble $\mathrm{IL}-2$ receptor $(747 \mathrm{U} / \mathrm{mL}$; normal range $135-483 \mathrm{U} / \mathrm{mL}$ ). Serum immunoelectrophoresis revealed no M-protein, and the levels of immunoglobulin $\mathrm{G}$ (IgG), IgM, IgA, and IgD were within normal range. Bone marrow aspiration showed no abnormalities.

The patient received R-CHOP chemotherapy (rituximab $375 \mathrm{mg} / \mathrm{m}^{2}$, cyclophosphamide $750 \mathrm{mg} / \mathrm{m}^{2}$, doxorubicin $50 \mathrm{mg} / \mathrm{m}^{2}$, vincristine $1.4 \mathrm{mg} / \mathrm{m}^{2}$, and prednisolone $50 \mathrm{mg} / \mathrm{m}^{2}$ for 5 days), 6 cycles every 3 weeks. At the end of 3 cycles of R-CHOP, complete remission (CR) was evaluated by computed-tomography imaging (Figure 3B), and the $\beta_{2}$-microglobulin and sIL-2R levels returned to their normal ranges.

Approximately 3 years after chemotherapy for extraosseous plasmacytoma, the patient experienced a complication from acute promyelocytic leukemia (APL). Chemotherapy with all-trans retinoic acid, cytarabine, and idarubicin was effective, and he showed CR from APL. Thereafter, chemotherapy mainly with cytarabine was repeated three times, and his CR status for APL is continuing. At present, the $\mathrm{CR}$ status for extraosseous plasmacytoma is being maintained for more than 7.5 years after R-CHOP chemotherapy.

\section{Discussion}

Although the clinical course of the extraosseous plasmacytoma is thought to be indolent, ${ }^{2}$ the progression presented here was so rapid that, at only 6 months after surgery, it recurred in several lymph nodes. This is because EBV-RNA was integrated into the tumor cells, which contained PBL components, although our patient was relatively young and healthy and was not immunodeficient, such as with HIV infection. EBV-RNA was detected in 15\% (3/20) of patients with extraosseous plasmacytoma of the head and neck, ${ }^{9}$ but the incidence outside of the head and neck region is unknown. Extraosseous plasmacytoma is difficult to diagnose in routine practice settings due to the morphological and immunohistochemical overlap with PBL. The adjective "plasmablastic" is used when there are more than $30 \%$ of plasmablasts in routine sections. ${ }^{10}$ In this case, plasmacytoma comprised the main lesion of the primary site. The proportion of PBL components was less than $30 \%$, leading to a diagnosis of plasmacytoma. Qing et $\mathrm{al}^{11}$ recently reported that PBL may occur as a high-grade transformation from extraosseous plasmacytoma. Our case may fall into this category; however, since the concept has not been established, more cases should be collected for further analysis.

Our case initially had a primary lesion of the ileum, with regional lymph node involvement. Morphologically, it seemed reasonable to assume that both lesions were the same tumor. The clonality analysis did not allow us to examine whether the ileal tumor and lymph node lesions had the same origin, because both samples had already been fixed by formalin. The ileal and lymph node lesions were CD20- and CD20+, respectively; in any event, the true cause of the difference in CD20 expression was unknown. Morphologically, CD20+ cells in lymph node lesions were found to be abnormal lymphocytes with marked dysplasia, suggesting neoplastic changes.

Extraosseous plasmacytoma is considered to be highly radiosensitive, and is commonly treated by irradiation and surgical resection, singly or in combination; the results of treatment are generally favorable. ${ }^{1,4}$ Of all plasma cell tumors, extraosseous plasmacytoma has the best prognosis, with a reported 5-year, recurrence-free survival rate of $81 \%{ }^{5}$ It has been suggested that chemotherapy should be limited to patients in whom extraosseous plasmacytoma has disseminated systemically, mass reduction is required preoperatively, or a local recurrence of a high-grade tumor is present after treatment. ${ }^{1,12,13}$ Our patient had the following characteristics: (1) EBV-RNA was integrated into tumor cells, which contained high-grade malignant features compatible with PBL. (2) CD20+ cells in regional lymph node lesions were present, and these cells were evaluated as neoplasia. (3) There was lymph node recurrence a relatively short period after surgery. We selected R-CHOP chemotherapy (a treatment for B-cell non-Hodgkin lymphoma) and successfully administered it to him. Because the tumor in our patient contained PBL components, the chemosensitivity of the tumor may have been higher than that of ordinary plasmacytoma. Subsequently, his course was complicated by APL, the treatment of which may have served as maintenance therapy for 
extraosseous plasmacytoma. Extraosseous plasmacytomas are often negative for CD20. ${ }^{1,3}$ Our search of the literature revealed no case reports of successful R-CHOP regimens for extraosseous plasmacytomas. We propose that chemotherapy can be an effective therapeutic agent in the management of extraosseous plasmacytomas with high-grade malignant components such as PBL. More case studies need to be performed to make it a standard recommendation.

\section{Disclosure}

The authors report no conflicts of interest in this work.

\section{References}

1. Alexiou C, Kau RJ, Dietzfelbinger H, et al. Extramedullary plasmacytoma: tumor occurrence and therapeutic concepts. Cancer. 1999;85: 2305-2014.

2. McKenna RW, Kyle RA, Kuehl WM, Grogan TM, Harris NL, Coupland RW. Plasma cell neoplasms. In: Swerdlow SH, Campo E, Harris NL, Jaffe ES, Pileri SA, editors. WHO Classification of Tumours of Haematopoietic and Lymphoid Tissues. 4th ed. Lyon, France: IARC; 2008:200-213.

3. Lin BT, Weiss LM. Primary plasmacytoma of lymph nodes. Hum Pathol. 1997;28:1083-1090.

4. Susnerwala SS, Shanks JH, Banerjee SS, Scarffe JH, Farrington WT, Slevin NJ. Extramedullary plasmacytoma of the head and neck region: clinicopathological correlation in 25 cases. Br J Cancer. 1997;75: 921-927.
5. Bachar G, Goldstein D, Brown D, et al. Solitary extramedullary plasmacytoma of the head and neck - long-term outcome analysis of 68 cases. Head Neck. 2008;30:1012-1019.

6. McKenna RW, Kyle RA, Kuehl WM, Grogan TM, Harris NL, Coupland RW. Plasmablastic lymphoma. In: Swerdlow SH, Campo E, Harris NL, Jaffe ES, Pileri SA, editors. WHO Classification of Tumours of Haematopoietic and Lymphoid Tissues. 4th ed. Lyon, France: IARC; 2008:256-257.

7. Colomo L, Loong F, Rives S, et al. Diffuse large B-cell lymphomas with plasmablastic differentiation represent a heterogeneous group of disease entities. Am J Surg Pathol. 2004;28:736-747.

8. Delecluse HJ, Anagnostopoulos I, Dallenbach F, et al. Plasmablastic lymphomas of the oral cavity: a new entity associated with the human immunodeficiency virus infection. Blood. 1997;89:1413-1420.

9. Aguilera NS, Kapadia SB, Nalesnik MA, Swerdlow SH. Extramedullary plasmacytoma of the head and neck: use of paraffin sections to assess clonality with in situ hybridization, growth fraction, and the presence of Epstein-Barr virus. Mod Pathol. 1995;8: 503-508.

10. Chang ST, Liao YL, Lu CL, Chuang SS, Li CY. Plasmablastic cytomorphologic features in plasma cell neoplasms in immunocompetent patients are significantly associated with EBV. Am J Clin Pathol. 2007; 128:339-344.

11. Qing X, Sun N, Chang E, French S, Ji P, Yue C. Plasmablastic lymphoma may occur as a high-grade transformation from plasmacytoma. Exp Mol Pathol. 2011;90(1):85-90.

12. Lattuneddu A, Farneti F, Lucci E, Garcea D, Ronconi S, Saragoni L. A case of primary extramedullary plasmacytoma of the colon. Int $J$ Colorectal Dis. 2004;19:289-291.

13. Pantelidou D, Tsatalas C, Margaritis D, et al. Extramedullary plasmacytoma: report of two cases with uncommon presentation. Ann Hematol. 2005;84:188-191.
International Journal of General Medicine

\section{Publish your work in this journal}

The International Journal of General Medicine is an international, peer-reviewed open-access journal that focuses on general and internal medicine, pathogenesis, epidemiology, diagnosis, monitoring and treatment protocols. The journal is characterized by the rapid reporting of reviews, original research and clinical studies across all disease areas.

\section{Dovepress}

A key focus is the elucidation of disease processes and management protocols resulting in improved outcomes for the patient.The manuscript management system is completely online and includes a very quick and fair peer-review system. Visit http://www.dovepress.com/ testimonials.php to read real quotes from published authors. 